\title{
An Analysis of the Factors Affecting the Incidental Vocabulary Acquisition in Reading
}

\author{
Ke Liu \\ Foreign Language Department \\ Huanghe Science and Technology College \\ Zhengzhou, China 450005
}

\begin{abstract}
Incidental acquisition vocabulary is an important way to enlarge vocabulary in reading, but there are some difficulties in improving the efficiency of vocabulary acquisition because reading can be affected by many factors. Therefore, the teacher should play a guiding role intentionally to adjust the various factors that affect vocabulary learning, so as to raise students' vocabulary learning awareness, making incidental vocabulary acquisition an effective means of vocabulary Learning.
\end{abstract}

\section{Keywords-vocabulary; acquisition; incidental}

\section{INTRODUCTION}

Since the 1980s, researches on incidental vocabulary acquisition have received more and more attention in the field of second language teaching and research. Through a large number of empirical researches, linguists generally believe that either L1 or L2 learners acquire most of their words in reading incidentally. However, incidental vocabulary acquisition is a complex psychological process subjecting to many factors. Whether the simple reading can bring forth the acquisition of vocabulary naturally, what are the problems in the process of vocabulary acquisition, and what are the factors that affect it? These will be the main focuses of the analysis and discussion in this paper.

\section{PROBLEMS IN INCIDENTAL VOCABULARY ACQUISITION}

Vocabulary acquisition in reading is considered to be a better method of vocabulary learning than direct instruction in classroom. Firstly, incidental vocabulary acquisition is more efficient, because reading and vocabulary acquisition can be carried out simultaneously. Secondly, since the words are learned in the context, learners would have a better understanding of the words. Thirdly, the process of learning is more personalized, for the reader can choose their own reading materials according to their interests.

However, some experts in L2 vocabulary acquisition research also pointed out the shortcomings of this approach. First of all, for beginners, the understanding of the target language is too difficult to guess from the meaning of words in the context, thus the vocabulary acquisition will not happen. Second, Many studies have shown that the full grasp of a word needs at least 5 to 6 times contacts. If learners have insufficient exposure to foreign language materials, the chance of incidental vocabulary acquisition will be reduced. Third, Understanding the meaning of a word from the context does not mean that the word is fully grasped, because the information he gets about the word is not comprehensive.

In order to solve these problems, we must first analyze the factors that affect its occurrence. Only in full understanding of these factors can we regulate the process of incidental vocabulary acquisition and to promote its effectiveness.

\section{FACTORS THAT AFFECT THE INCIDENTAL VOCABULARY ACQUISITION IN READING}

\section{A. Vocabulary Size}

An important factor influencing vocabulary incidental acquisition is the size of learners' vocabulary. In an article, words are interconnected, so the meaning of a word is determined based on its surrounding words or the context. Learners with a large vocabulary size can make full use of the semantic relations and context-activated mental schemas during the reading process to make reasonable inferences about the new words encountered. However, the learners with a small vocabulary size can hardly use the context clues to guess words, because these clues are unfamiliar to them.

How many words do learners need to learn in order to implement incidental vocabulary acquisition? Many scholars have conducted many studies on this issue, and Nation's research shows that the rate of known words in reading can reach $90 \%$ when a learner masters 2000 to 5000 words. According to the survey, Nation proposed that at least $95 \%$ of the words in an article should be known in order to understand the general idea of the article; and a complete understanding of an article might require a reader to make accurate inference of words or phrases, so the rate of known words should reach $98 \%$. In addition, according to Laufer's Threshold hypothesis, the minimum requirement to understand an article is that $95 \%$ of the words in an article should be known, the threshold level should be 5000 words. If the level is below the threshold level, the reader will have difficulty understanding the text. And if it is above it, the reader will be able to skillfully use the reading strategy to achieve better comprehension in reading. 


\section{B. Input}

From the perspective of psychological cognition, the process of reading comprehension involves the complex interaction between the reader and the text. In this process, the reader uses contextual knowledge or context to decode the textual information. Different levels of reading comprehension include different cognitive processing. The deeper the cognitive processing, the better the reader's understanding of the text. Based on this principle, Laufer \& Hulstijn proposed the "Involvement Load Hypothesis". They argue that the effects of incidental vocabulary acquisition have a close relationship with reading tasks. For different reading tasks, the efforts that learners put in (ie, input) are not the same. "Input" can be measured in three ways, namely "need", "search" and "evaluation". "Demand" refers to the learning motivation of the learner, "search" means to find out the meaning of a new word by looking up a dictionary or communicating with others. "Assessment" means comparing a word with other words to determine the word meaning. Different learning tasks can use these three factors to measure the size of input. The greater the amount of input, the deeper the learners' processing of new words and the better the effect of vocabulary acquisition is.

Laufer \& Hulstijn provided experimental evidence for the hypothesis. They conducted a research with 186 Englishspeaking subjects who were randomly assigned with three tasks: (1) reading comprehension, (2) reading and cloze (3) writing with the target words. Upon completion of the task, the subjects participated in two vocabulary tests; the purpose is to test their memory of the target word. After the analysis of the data, the conclusion is that "writing" contributed greatly to the incidental vocabulary acquisition, followed by "reading and cloze", and "reading" contributes the least. The results of this experiment support their "Involvement Load Hypothesis". In the reading process, by checking the dictionary or reference notes to determine the meaning of words, readers can deepen the processing of new words, thus increasing the amount of input. Many scholars have investigated the role of dictionaries and notes in incidental vocabulary acquisition.

Fraser's research shows that looking up a dictionary to determine a word's meaning is a effective method of mastering the word. Combining inferring and checking the dictionary can give rise to $50 \%$ of the memory of a word. DAN Shi-ping and YAN Chen-song have conducted empirical studies on the effect of multiple choice annotations on incidental vocabulary acquisition. The results show that the multiple choice annotations and single item annotations have significant effects on incidental vocabulary acquisition, and multiple choice annotations are more conducive to vocabulary incidental acquisition.

\section{Guessability}

Guessability is an ability to guess words in context, which is a foreign language learning ability and plays an important role in learners' reading ability and the effect of vocabulary acquisition. It has a close relationship with vocabulary size. According to Laufer, L1 and L2 learners differ in their ability to guess words, mainly because L1 learner has a larger vocabulary size. In order to guess the meaning of new words, learners must know the words around the new words, because L1 learners have a large vocabulary size which enable them have a good understanding of the reading materials, so they can make use of existing clues for guessing. If the learner's vocabulary coverage is less than $95 \%$, too many new words in the text will hinder the reader's understanding of the article, thus causing great difficulty in guessing the word. In addition to vocabulary, the use of guessing word strategy to guess the word also has a great impact. On the basis of the same vocabulary size, learners who are good at using the wordguessing skills have a relatively high ability to guess words. Guessing word strategy refers to the skills of guessing word meaning when encountering new words in the reading process based on some related information, such as affix, context and background knowledge. In order to carry out efficient reading and vocabulary learning, the ability to use various guessing strategies is indispensable. Hustijin examined in one study the relationship between guessability and vocabulary acquisition. Her subjects are foreign language learners in English who accepted the test of guessing word ability test and vocabulary test. It was found that the students who scored higher than the average score in the test of guessability did well in the vocabulary test than the students whose score was lower than the average, and the difference was significant. Hustijin concludes that students with better ability to guess words can learn a lot of words in reading, and they are more likely to expand their vocabulary than those who are less skilled in guessability.

\section{Contextual Clues}

The understanding of any text can not achieved without a certain context, the clues in which play a very important role in the understanding of the text. Rich contextual clues can help the reader to infer the meaning of the word successfully and thus facilitate the acquisition of incidental vocabulary. If the context does not give sufficient contextual clues, it is difficult for the reader to speculate on the meaning of the new word from the context. However, some contexts may mislead the reader into the wrong conclusions, which will hinder the reader's understanding of the text, thus reducing the effect of incidental vocabulary acquisition. Bruce Lee designed an experiment to try to find out the effect of contextual clues on guesswork and lexical memory. In the experiment, he categorized the sentences into two categories: "cues-adequate sentence" and "cues-inadequate sentences" according to contextual clues, and then divided the 48 subjects into four groups, two groups accepted the "prompt sentence" test, the other two groups to accept the "nonprompt sentence" test, and then tested the guessability and word memory. The results of the analysis showed that the subjects who accepted the "prompt Sentence" test group were more accurate in guessing the word meaning and had better memory effect. Thus, he concludes that the higher the score of guessing semantics in the context, the better the vocabulary memory.

It follows that the acquisition of vocabulary in reading depends on: 
- Whether the vocabulary of the learner reaches the threshold level;

- Whether there is enough input through reading;

- Whether the learner possesses some learning strategies in word learning;

- Whether there are enough contextual clues in the discourse.

These four aspects are fundamental and critical in ensuring the efficiency of incidental vocabulary acquisition.

\section{The EnLightenment to VocabUlary Teaching}

For a long time, some teachers believe that reading itself is an effective way to learn vocabulary, thus ignoring the factors that affect reading. The author believes that in order to improve the efficiency of incidental vocabulary acquisition in reading, teachers need take measures from the following three aspects:

\section{A. Expanding Reading}

Almost all scholars believe that a large number of readings can improve the efficiency of incidental vocabulary acquisition, the most famous is Ellie's "book flood", a large number of subjects ranging from one hundred People to thousands of people take part in the experiment in a period of one to three years. The results showed that the subjects' language skills were significantly improved, especially the lexical knowledge. There are two ways to expand the reading volume, one is to read materials assigned by teachers, and the other is choosing reading material by students themselves. However, when choosing reading materials, students' reading level should be taken into account. Teachers should play a guiding role in choosing classified reading for vocabulary acquisition. In these simple books and materials, there are generally more than $95 \%$ of the words are familiar to learners. Students can choose according to their own level, suitable for their own reading.

\section{B. Cultivating Students' Strategy of Word Processing}

Most of the students pay more attention to the meaning of the text and tend to ignore the new words, which is not conductive to the acquisition of vocabulary, and also results in difficulties in reading comprehension due to the missing of important information, thereby reducing the interest of students in reading. Therefore, teachers should pay attention to enhance students' awareness of new words, and guide them to be aware of new words. In addition, teachers should also cultivate the students' word-guessing strategy to capture a variety of clues, such as synonyms, antonyms, context information, etc. The word itself also contains abundant information, and it is also an effective method to guess the word meaning according to the word formation method such as prefix, suffix, etc. In addition, the theme of the article also provides a lot of background information, which is helpful to infer the meaning of the new words.

\section{Enhancing Reading Instruction}

In order to improve the efficiency of incidental learning, teachers also need to give useful instruction to students in reading, there are two specific ways: First, students acquire words in the enhanced conditions, and second, students acquire words under non-enhanced condition. In the first approach, the student learn words by reading an essay and answering incidental comprehension questions, followed by a series of vocabulary exercises. In the second way, students also need to read an article and answer the reading comprehension questions attached. However, they do not do any vocabulary exercises, instead, they read an article containing the original words of the article, so that students will be familiar with some words through further reading. The advantage of reading instruction is that, on the one hand, students can deepen the understanding and memorization of words in context; on the other hand, they can master the use of words through various vocabulary exercises.

\section{CONCLUSION}

In summary, incidental vocabulary acquisition efficiency depends on reading materials, reading tasks and learners' proficiency. In college English teaching, incidental vocabulary acquisition is greatly restricted by students' limited vocabulary and inability of self-learning, so teachers should be conscious of the constraints of vocabulary learning, raising students' vocabulary learning awareness, applying vocabulary learning strategies to reading, thus making incidental vocabulary acquisition an effective means of vocabulary learning.

\section{REFERENCES}

[1] Craik, F. I. M. \& Lockhart, R. S. Depth of Processing: A framework for memory research $[\mathrm{J}]$. Journal of Verbal L earning and Verbal Behavior, 1972(11): 671-684.

[2] Nation, P. \& R. Waring. Vocabulary Size, Text Coverage, and Word Lists [C] In N. Schmitt, \& M. McCathy (eds). Vocabulary Description, Acquisition and Pedagogy. Cambridge: Cambridge University Press, 1997.

[3] Laufer, B. \& Hulstijn, J. Incidental vocabulary acquisition in a second language: The construct of task-induced involvement [J]. Applied Linguistics, 2001(22): 1-26.

[4] Fraser, C. A. Lexical processing strategy use[J]. Studies in Second Language Acquisition, 1999(21): 225-241.

[5] Li, Xiaolong. Effects of contextual cues on inferring and remembering meanings of new words[J]. Applied Linguistics, 1988 (9): 401-413.

[6] Mondria, J. \& Witde Boer. The effects of contextual richness on the guessability and the retention of words in a foreign language[J]. Applied Linguistics, 1991(12): 249-267. 